\title{
Article
}

\section{Chagas Disease in Pregnant Women from Endemic Regions Attending the Hospital General de Mexico, Mexico City}

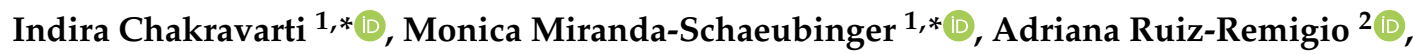 \\ Carlos Briones-Garduño ${ }^{3}$, Edith A. Fernández-Figueroa ${ }^{2,4}$, Concepción Celeste Villanueva-Cabello ${ }^{2}$, \\ Alejandra Borge-Villareal ${ }^{3}$, Yadira Bejar-Ramírez ${ }^{5}$, Alejandro Pérez-González ${ }^{5}$, César Rivera-Benitez ${ }^{6}$, \\ Eyal Oren $\left.{ }^{7}{ }^{(}\right)$, Heidi E. Brown ${ }^{8}{ }^{\circ}$, Ingeborg Becker ${ }^{2, *}$ and Robert H. Gilman ${ }^{1}$
}

\section{check for}

updates

Citation: Chakravarti, I.; Miranda-Schaeubinger, M.; Ruiz-Remigio, A.; Briones-Garduño,

C.; Fernández-Figueroa, E.A.;

Villanueva-Cabello, C.C.;

Borge-Villareal, A.; Bejar-Ramírez, Y.; Pérez-González, A.; Rivera-Benitez,

C.; et al. Chagas Disease in Pregnant

Women from Endemic Regions

Attending the Hospital General de

Mexico, Mexico City. Trop. Med. Infect.

Dis. 2022, 7, 8. https://doi.org/

$10.3390 /$ tropicalmed7010008

Academic Editor:

Carlos Franco-Paredes

Received: 17 November 2021

Accepted: 7 December 2021

Published: 11 January 2022

Publisher's Note: MDPI stays neutral with regard to jurisdictional claims in published maps and institutional affiliations.

Copyright: (c) 2022 by the authors Licensee MDPI, Basel, Switzerland. This article is an open access article distributed under the terms and conditions of the Creative Commons Attribution (CC BY) license (https:// creativecommons.org/licenses/by/ $4.0 /)$
1 Department of International Health, Johns Hopkins School of Public Health, Baltimore, MD 21215, USA; rgilman1@jhu.edu

2 Centro de Medicina Tropical, División de Investigación, Facultad de Medicina, Universidad Nacional Autónoma de México, Ciudad de México 04510, Mexico; ruizad11@hotmail.com (A.R.-R.); eafernandez@inmegen.edu.mx (E.A.F.-F.); concepcioncelestevillanueva@gmail.com (C.C.V.-C.)

3 Servicio de Ginecología y Obstetricia, Hospital General de México "Dr. Eduardo Liceaga", Ciudad de México 06720, Mexico; drcarlosbriones@yahoo.com.mx (C.B.-G.); aborge.villarreal20@gmail.com (A.B.-V.)

4 Computational and Integrative Genomics, National Institute of Genomic Medicine, Ciudad de México 14610, Mexico

5 Banco de Sangre, Hospital General de México “Dr. Eduardo Liceaga”, Ciudad de México 06720, Mexico; yadira_bejarr@yahoo.com.mx (Y.B.-R.); jalex_perezg@hotmail.com (A.P.-G.)

6 Servicio de Infectología, Hospital General de México “Dr. Eduardo Liceaga”, Ciudad de México 06720, Mexico; rivera.cesar85@gmail.com

7 Division of Epidemiology and Biostatistics, School of Public Health, San Diego State University, San Diego, CA 92182, USA; eoren@sdsu.edu

8 Mel and Enid Zuckerman College of Public Health, University of Arizona, Tucson, AZ 85724, USA; heidibrown@arizona.edu

* Correspondence: indira.chakravarti@gmail.com (I.C.); monicamirs@gmail.com (M.M.-S.); becker@unam.mx (I.B.)

Abstract: Trypanosoma cruzi infection leads to Chagas disease (CD), a neglected tropical infection of significant public health importance in South and Central America and other, non-endemic, countries. Pregnant women and their children are of particular importance to screen as T. cruzi can be transmitted vertically. The objective of this study was to screen for T. cruzi infection among pregnant women from endemic areas seen at the Hospital General de Mexico for prenatal care, so that they and their children may be quickly connected to $C D$ treatment. Pregnant women were recruited through the hospital prenatal clinic and screened for T. cruzi infection using a series of serological and molecular tests. Of 150 screened patients, mean age 26.8 (SD 6.4), 30 (20.0\%) were positive by at least one diagnostic test. Of these, only nine $(6 \%)$ were positive as determined by PCR. Diagnosis of chronic $\mathrm{CD}$ is difficult in endemic places like Mexico due to the limitations of current commercially available diagnostic tests. Further evaluation of diagnostic performance of various assays could improve current $\mathrm{CD}$ diagnostic algorithms and proper care management in these regions. Genetic variability in the parasite may also play a role in the differing assay performances seen in this study, and this may be a valuable avenue of further research.

Keywords: Chagas disease; congenital Chagas disease; Trypanosoma cruzi; Chagas disease diagnosis

\section{Introduction}

Chagas disease (CD) is a neglected tropical disease caused by the parasite Trypanosoma cruzi. Over six million people worldwide are affected, mostly in South and Central America, where the parasite and its vector are endemic [1]. T cruzi is carried in the gastrointestinal tract of triatomine bugs (Family Reduviidae, subfamily Triatominae). The parasite is 
transmitted to humans when the insects defecate into a bite, wound, or mucosal surface. The parasite may also be transmitted vertically from an infected mother to their child (congenital infection). When left untreated or treated too late, CD may result in cardiac or gastrointestinal disease, or both [2].

Chagas disease begins with an acute phase before moving to the chronic phase. Most acute infection patients are asymptomatic or experience nonspecific febrile symptoms [3], and therefore remain undetected. Most remain asymptomatic during the chronic phase of the disease and are called "indeterminate" cases. The chronic phase of the disease is characterized by low-level parasitemia and an IgG antibody-based immune response [3]. Between 20 to $30 \%$ of chronic CD patients become symptomatic and develop cardiac, gastrointestinal, or cardio-digestive symptoms [4].

T. cruzi is considered endemic in Mexico, where the WHO estimates a prevalence of nearly $0.800 \%$ [5]. However, this average misrepresents the wide prevalence variation across the country; regional CD prevalence across Mexico ranges from $0.36 \%$ to $20 \%$ [6]. CD prevalence is generally higher in rural regions [7]. Similarly, disease burden varies across Mexico, with high incidence rates reported in Yucatán (4.0 per 100,000 people), Oaxaca (2.4) and Hidalgo (2.1) [8].

\subsection{T. cruzi Infection and Pregnancy}

Congenital infection occurs in 1-5\% births [9]. Adverse maternal and fetal outcomes associated with T. cruzi infection include low Apgar scores, poor fetal growth, low birthweight, premature birth, and miscarriage [10]. Congenital T. cruzi infection is associated with myocarditis, meningoencephalitis, and/or respiratory distress [11-14]. Vertical transmission rates vary by community, though many studies report rates between 1 and $10 \%[11-13,15,16]$. While overall improvement in maternal health seems to reduce complications, vertical transmission rates remain constant [10]. Congenital Chagas is estimated to account for $22 \%$ of all new T. cruzi infections globally [17]. If left untreated, infected infants are presumed to carry the same $20-30 \%$ lifetime risk of cardiac or gastrointestinal disease as infected adults [14]. Early detection in pregnant women is essential for identifying and treating congenital infection.

\subsection{Diagnosis of $C D$}

Diagnosis is made by a series of immunological or molecular tests. Acute T. cruzi infection may be diagnosed with direct visualization of the parasite in blood smears, among other methods. Diagnosis of chronic infection relies on the identification of antibodies against parasite antigens, as parasitemia wanes during the chronic phase. The WHO recommends that chronic $C D$ diagnosis be made with two different serological tests, and a third if the first two are inconsistent [18]. Commonly-used serological tests include enzyme-linked immuno-sorbent assays (ELISAs), immunofluorescence assays, and immuno-blots. However, many of these tests are not readily available in most clinical settings [19]. Furthermore, many serological tests have been shown to perform differently in different geographic regions, in Mexico and across other Latin American countries [20-22].

\subsection{Barriers to CD Diagnosis and Goals of Study}

Diagnosis of CD is complicated by the technical shortcomings of diagnostic tests and poor access to healthcare. Furthermore, most cases are not diagnosed at birth due to the lack of accurate and timely diagnostic tests and because the disease burden is underestimated [23-25].

There are many obstacles to screening for T. cruzi infection in both endemic and nonendemic countries. A significant barrier is regional heterogeneity in disease prevalence, which creates an unclear picture of disease risk within a country or region [6]. Genetic diversity of the parasite may also create challenges for accurate diagnosis [19]. Lastly, the largest barrier is the lack of awareness of $\mathrm{CD}$ in both healthcare professionals and 
patients $[26,27]$. These factors all lead to less than $1 \%$ of CD patients worldwide receiving treatment [28].

Given the significant health problems associated with congenital CD and the advantages of early detection in preventing subsequent gastrointestinal and cardiac disease, it is crucial to identify cases as early as possible. The goal of this study was to screen pregnant women from endemic regions for T. cruzi infection seen at the Hospital General de Mexico, so that preventive treatment could be provided to women and infants.

\section{Materials and Methods}

The study protocol was approved by the National Autonomous University of Mexico (UNAM) ethics board, project number 139-2017, and by the ethics committee of the Hospital General No. HGM-DG-114-DI-2019. Written informed consent was obtained from all individuals at the time of screening.

This study took place in the Hospital General de Mexico (HGM), in Mexico City from February 2018 to February 2019. Participants were eligible for screening if they were: pregnant, 14 years of age or older, and from a Chagas-endemic Mexican state (Aguascalientes, Chiapas, State of Mexico, Guanajuato, Guerrero, Hidalgo, Jalisco, Michoacán, Morelos, Nayarit, Oaxaca, Puebla, Querétaro, Quintana Roo, Sinaloa, Tabasco, Tamaulipas, Tlaxcala, Veracruz, Yucatán, Zacatecas; based on Sistema Nacional de Vigilancia Epidemiológica/National Epidemiologic Surveillance System) or any endemic country. Additional inclusion criteria were pregnant women with heart disease or recurrent spontaneous abortions. Potential participants were excluded if they were not from an endemic region or if they declined to participate. Study recruitment occurred through direct participant enrollment at the time of prenatal care visits. In addition, flyers were posted in obstetrics ward waiting rooms notifying potential participants of the study. Recruitment and the subsequent consent process were carried out by trained study staff members.

During the study visit, a socio-demographic questionnaire designed to identify factors associated with T. cruzi infection was administered to each participant. Results were anonymized and recorded in an electronic REDCap database [29,30]. The information collected included clinical and epidemiological characteristics such as age, sex, state of origin, household characteristics, exposure to the triatomine bug, and questions about previous blood transfusions or organ transplantation.

Venipuncture was performed during the initial study visit, and sera were stored at $-20{ }^{\circ} \mathrm{C}$. An initial screening was done with the ELISA test using antigens grown inhouse [31]. All samples were additionally sent to the blood bank of the General Hospital for confirmatory testing with either the ABBOTT PRISM Chagas chemiluminescent immunoassay or the Bio-Rad Chagascreen ELISA. The ABBOTT and Bio-Rad tests are commonly used serological tests for T. cruzi infection. Considering the variability by location of tests' performance [20-22], this in-house ELISA was chosen as a screening method because its antigens were grown using local parasite strains, as detailed below.

All positive or indeterminate patients by any of the mentioned tests were then tested with InBios Chagas Detect Plus rapid test, Accutrack Chagas Recombinant micro-ELISA test and qPCR (Figure 2). Forty samples that had negative results with the "in house" ELISA and the tests run by the hospital blood bank (i.e., the ABBOTT PRISM Chagas assay or the Bio-Rad Chagascreen ELISA), were randomly selected to be tested with the Inbios Chagas Detect Plus rapid test.

\section{1. "In-House" ELISA Test Antigen Preparation}

Trypanosoma cruzi Queretaro strain TBAR/MX/0000/Queretaro (“Qro") epimastigotes were maintained in liver infusion tryptose culture medium (LIT), supplemented with $10 \%$ heat-inactivated fetal bovine serum in axenic conditions at $28^{\circ} \mathrm{C}$ [32]. For antigen preparation, epimastigotes were washed in cold PBS, centrifuged, and resuspended in $50 \mathrm{mM}$ Tris- $\mathrm{HCl}$ at $\mathrm{pH} 7.4$ with protease inhibitors (aprotinin: $10 \mu \mathrm{g} / \mathrm{mL}$, leupeptin: $2 \mu \mathrm{g} / \mathrm{mL}$ and benzamidine: $1 \mathrm{mM}$ ). They were sonicated in cold with 6 cycles of $1 \mathrm{~min}$. 
Effective cell lysis was verified through light microscopy. The samples were centrifuged at $30,600 \times g$ at $4{ }^{\circ} \mathrm{C}$ for $1 \mathrm{~h}$. Supernatants were collected and their protein quantified by Bradford assay. Aliquots of $20 \mu \mathrm{L}$ were stored at $-70{ }^{\circ} \mathrm{C}$ until testing.

\section{2. "In House" ELISA Test Antigen Detection}

The in-house ELISA test was made with $0.6 \mu \mathrm{g}$ of prepared T. cruzi Qro-strain antigen diluted in $100 \mu \mathrm{L}$ of PBS per well and fixed one hour on a 96 well EIA/RIA plate at room temperature (modified by Ryan et al., 2002) [33]. The antigen was then discarded and blocked with $200 \mu \mathrm{L}$ of blocking solution for one hour at room temperature. Patient sera were analyzed in triplicate. They were diluted 1:100 in blocking solution and 100 $\mu \mathrm{L}$ were added per well and incubated for two hours at room temperature. The sera were discarded, the ELISA plate was washed 4 times with $300 \mu \mathrm{L}$ PBS-Tween per well in an automated plate washer. The peroxided secondary antibody (HRP-rabbit anti human IgA, IgG, IgM, Kappa, Lambda) was diluted 1:12,000 and $100 \mu \mathrm{L}$ were added per well for $30 \mathrm{~min}$ at room temperature. The secondary antibody was discarded by washing and tetramethylbenzidine (TMB) peroxidase substrate and peroxidase solution $B$ were mixed in equal volumes and added using $100 \mu \mathrm{L}$ per well. The plate was incubated with this solution for $30 \mathrm{~min}$ at room temperature, protected from light. The enzymatic reaction was stopped using $100 \mu \mathrm{L}$ of phosphoric acid $1 \mathrm{M}$. Results were obtained by examining the plate in an EIA plate reader at $450 \mathrm{~nm}$. The Cut-Off value was determined by the following formula: 3X standard deviation sample + negative control average. The results were calculated by subtracting the Cut-Off value from the average of the three serum samples. The samples were considered positive if their OD values were at least $10 \%$ higher than their Cut-Off. The samples were negative if their OD values were at least $10 \%$ lower than their Cut-Off and indeterminate if OD values were within $10 \%$ of the Cut-Off value.

\subsection{Accutrack Chagas Recombinant MicroELISA Test, Lemos Laboratory, Buenos Aires, Argentina}

This is an immunoenzymatic assay with recombinant antigens and was used according to the technical specifications in the product [34].

\subsection{Chagas Detect ${ }^{T M}$ plus Rapid Test}

This is a rapid immunochromatographic strip assay for the qualitative detection of human IgG antibodies to T. cruzi in human serum. This rapid test was used according to the technical specifications in the product [35].

\section{5. $q P C R$ and DNA Blood Extraction}

PCR was conducted on samples with positive results, indeterminate results, and four random negative samples. Blood samples $(10 \mathrm{~mL})$ were mixed with one volume of Guanidine Hydrochloride 6 M, EDTA $0.2 \mathrm{M}$ buffer, $\mathrm{pH} 8.00$ (GE) and boiled for $10 \mathrm{~min}$ at $98^{\circ} \mathrm{C}$. Blood treated with GE (GEB) and serum samples were processed for DNA extraction using the High Pure PCR Template Preparation kit (Roche Diagnostics Corp., Indiana, IN, USA), following the recommendations of the manufacturer. Binding buffer ( $200 \mu \mathrm{L})$, proteinase $\mathrm{K}(20 \mu \mathrm{L})$ and $300 \mu \mathrm{L}$ of the sample (GEB or serum) were mixed and incubated during $10 \mathrm{~min}$ at $70^{\circ} \mathrm{C}$. Isopropanol $(100 \mu \mathrm{L})$ was added, mixed and the sample was placed in a filter tube assembled in a collection tube and centrifuged at $8000 \times g$ for $1 \mathrm{~min}$. The filter tube with the sample was washed once with inhibitor removal buffer $(500 \mu \mathrm{L})$ and twice with washing buffer $(500 \mu \mathrm{L})$ and centrifuged. The filter tube was dried by centrifugation at $8000 \times g$ for $1 \mathrm{~min}$. Samples were eluted with $100 \mu \mathrm{L}$ of elution buffer at $70{ }^{\circ} \mathrm{C}$ [34]. Samples were extracted in duplicate.

\subsection{Multiplex Real-Time PCR Assay}

Real-Time multiplex PCR for identification of T. cruzi in the biological samples was performed using TaqMan probes reported to detect satellite DNA (SatDNA) of the parasite, and human RNAse P gene was used for quality control (Table S1). All PCR reactions 
were carried out with $5 \mu \mathrm{L}$ of DNA in a final volume of $20 \mu \mathrm{L}$. All PCR reactions were carried out with $5 \mu \mathrm{L}$ of DNA in a final volume of $20 \mu \mathrm{L}$. The reaction mixture included: $10 \mu \mathrm{L}$ of Universal PCR Master mix $2 \times$ (Applied Biosystems), $1 \mu \mathrm{L}$ of cruzi1 and cruzi2 oligonucleotides $(10 \mu \mathrm{M}), 0.2 \mu \mathrm{L}$ of cruzi3 $(5 \mu \mathrm{M}), 0.5 \mu \mathrm{L}$ of RNAse P 20× (Applied Biosystems) and $1.3 \mu \mathrm{L}$ of RNAse-free water. Optimal cycling conditions for the qPCR assay were initially $10 \mathrm{~min}$ at $95^{\circ} \mathrm{C}$, followed by 40 cycles at $95^{\circ} \mathrm{C}$ for $15 \mathrm{sec}$ and $58^{\circ} \mathrm{C}$ for 1 min (with data collection) in an Applied Biosystems (ABI 7500 Fast) device [36]. Samples were analyzed in duplicate.

\subsection{Statistical Analysis}

Descriptive statistics were conducted using the statistical software Stata 14.38 [37].

\section{Results}

Overall, 150 patients consented to participate and provided samples for analysis, mean age 26.8 (SD 6.4). Most (97.9\%) came from Mexico, primarily Mexico City (40\%), State of Mexico (31.3\%), Guerrero (6\%), and Puebla (4.6\%); the state of origin for Mexican patients along with their screening test result may be found in Figure 1. Two patients were from Venezuela $(1.3 \%)$ and one from Colombia (0.6\%). All 147 of the Mexican participants completed the survey. Few had heard of CD; 25 (16.9\%) and $23(15.54 \%)$ had seen a triatomine, and only one $(0.68 \%)$ reported knowledge of being bitten by a triatomine.

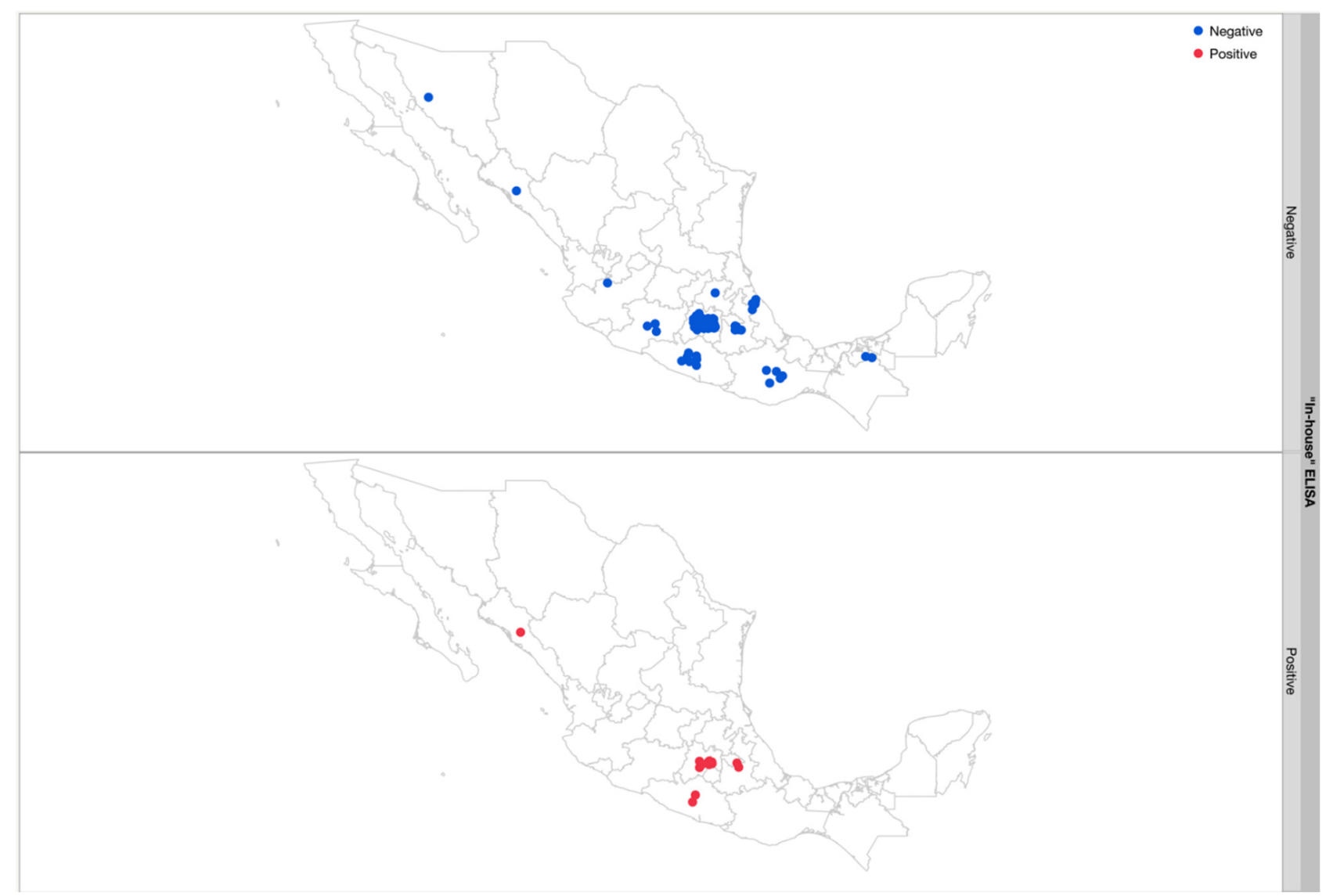

Figure 1. States of origin of patients with positive and negative results from the CD screening test ("in-house" ELISA) used at HGM.

Of the 150 participants tested, $17(11.3 \%)$ were positive and $5(3.3 \%)$ were indeterminate by the in-house ELISA screening test. Of these 22, 14 (63.6\%) were positive by the InBios rapid test, $2(9.1 \%)$ by Accutrack, $1(4.5 \%)$ by the blood bank tests and $9(40.1 \%)$ were positive by PCR. 
Regardless of screening test results, two (1.3\%) were positive by the Accutrack ELISA, $23(15.3 \%)$ were positive by InBios, $9(6 \%)$ were positive by PCR, and $1(0.7 \%)$ by Chagascreen. Sixteen samples (10.7\%) were positive by at least two tests (Figure 2). Five (3.3\%) were positive by the in-house ELISA, the InBios rapid test, and at least one other test. Thirty $(20.0 \%)$ were positive by at least one test (Table 1$)$.
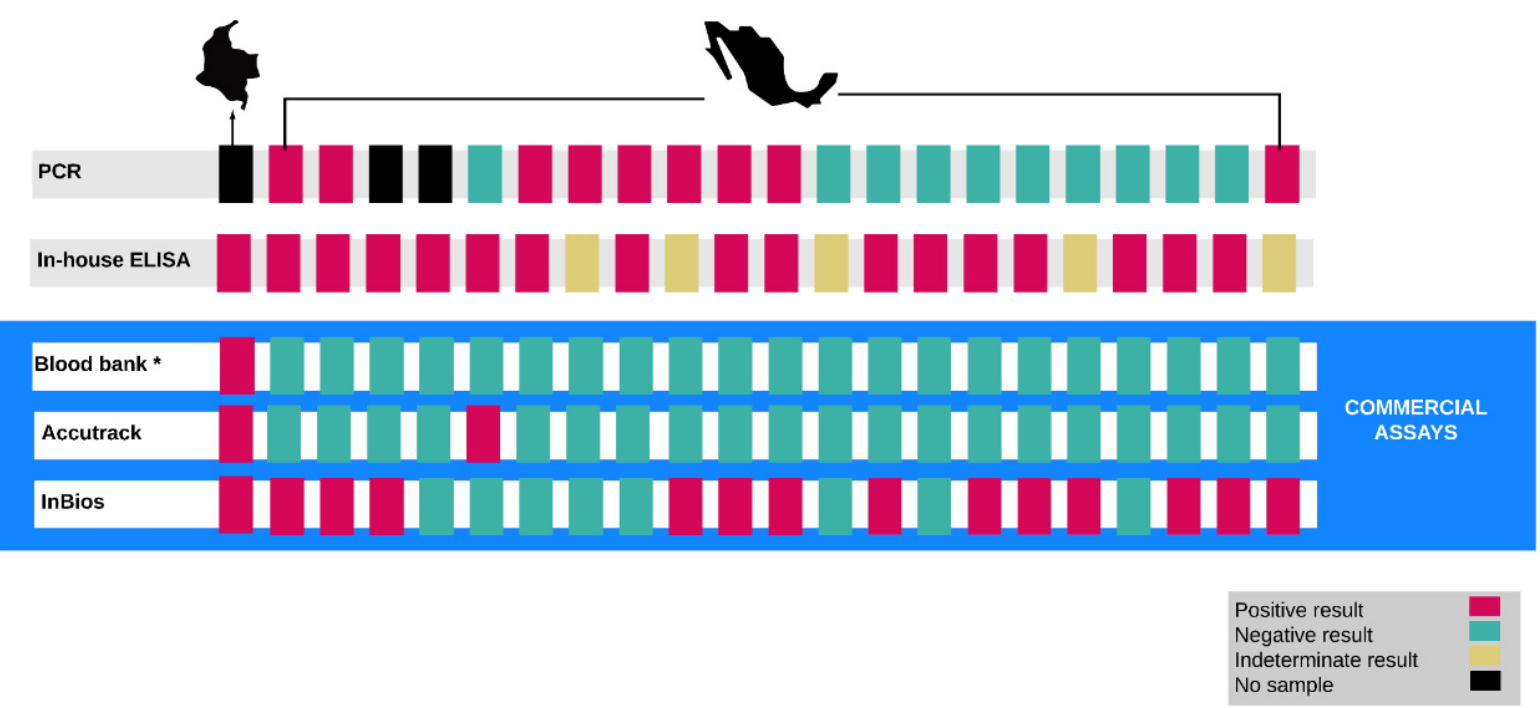

Figure 2. CD test results of participants with positive or indeterminate results by in house ELISA. * Blood bank tests include: ABBOTT PRISM Chagas assay or BioRad Chagascreen ELISA. Of these, 12 were positive by the WHO-defined criteria of having at least two different serological tests in agreement; nine were positive by qPCR. Three participants could not successfully be reached for further blood draws, and so no sample was available to run PCR on these patients. The country of origin of these patients is indicated at the top of the figure (Colombia, left; Mexico, right).

Table 1. Positive results by test type.

\begin{tabular}{|c|c|c|c|c|}
\hline & Test & Indeterminates ${ }^{1}$ & Positives $^{2}$ & $\%$ Positive $^{3}$ \\
\hline Blood bank tests & $\begin{array}{l}\text { ABBOTT PRISM Chagas assay } \\
\text { BioRad Chaga-screen ELISA }\end{array}$ & $\begin{array}{c}0 / 42=0 \% \\
0 / 108=0 \%\end{array}$ & $\begin{array}{c}0 / 42=0 \% \\
1 / 108=0.93 \%\end{array}$ & $1 / 150=0.67 \%$ \\
\hline Laboratory tests & $\begin{array}{c}\text { In-house ELISA } \\
\text { Inbios Chagas Detect Plus } \\
\text { Lemos Labs. Accutrak Recombinant ELISA } \\
\text { qPCR }\end{array}$ & $\begin{array}{c}5 / 150=0.3 \% \\
\text { N/A } \\
\text { N/A } \\
\text { N/A }\end{array}$ & $\begin{array}{c}17 / 150=11.3 \% \\
23 / 64=36.0 \% \\
2 / 25=8 \% \\
9 / 23=39.1 \%\end{array}$ & $\begin{array}{c}17 / 150=11.3 \% \\
23 / 150=15.3 \% \\
2 / 150=1.3 \% \\
9 / 150=6 \%\end{array}$ \\
\hline
\end{tabular}

${ }^{1}$ Samples yielding indeterminate results with this test, out of all samples tested with this test. ${ }^{2}$ Samples yielding positive results with this test, out of all samples tested with this test. ${ }^{3}$ Positive samples by this test as a percentage of all samples.

Among the positive tests, results were highly discrepant across the different tests. Nine patients (6\%) were positive by the most specific test alone (PCR) (Figure 2). When compared to serologic tests, none of the PCR-positives were positive by Accutrack ELISA. Even though $23(15.3 \%)$ of the patients tested by the FDA-approved InBios rapid test were positive, only six of these cases were also positive by PCR.

Using the WHO diagnostic criteria for chronic CD of agreement between at least two different serological assays (here, the in-house ELISA, the Accutrak ELISA, the InBios rapid test, the Abbott Prism, or the BioRad Chagascreen), 12 samples (8\%) were positive; of these 12 samples, 4 were positive by PCR (Figure 3).

Nine of the 23 samples positive by the Inbios rapid test, tested negative using all other diagnostic tests. 


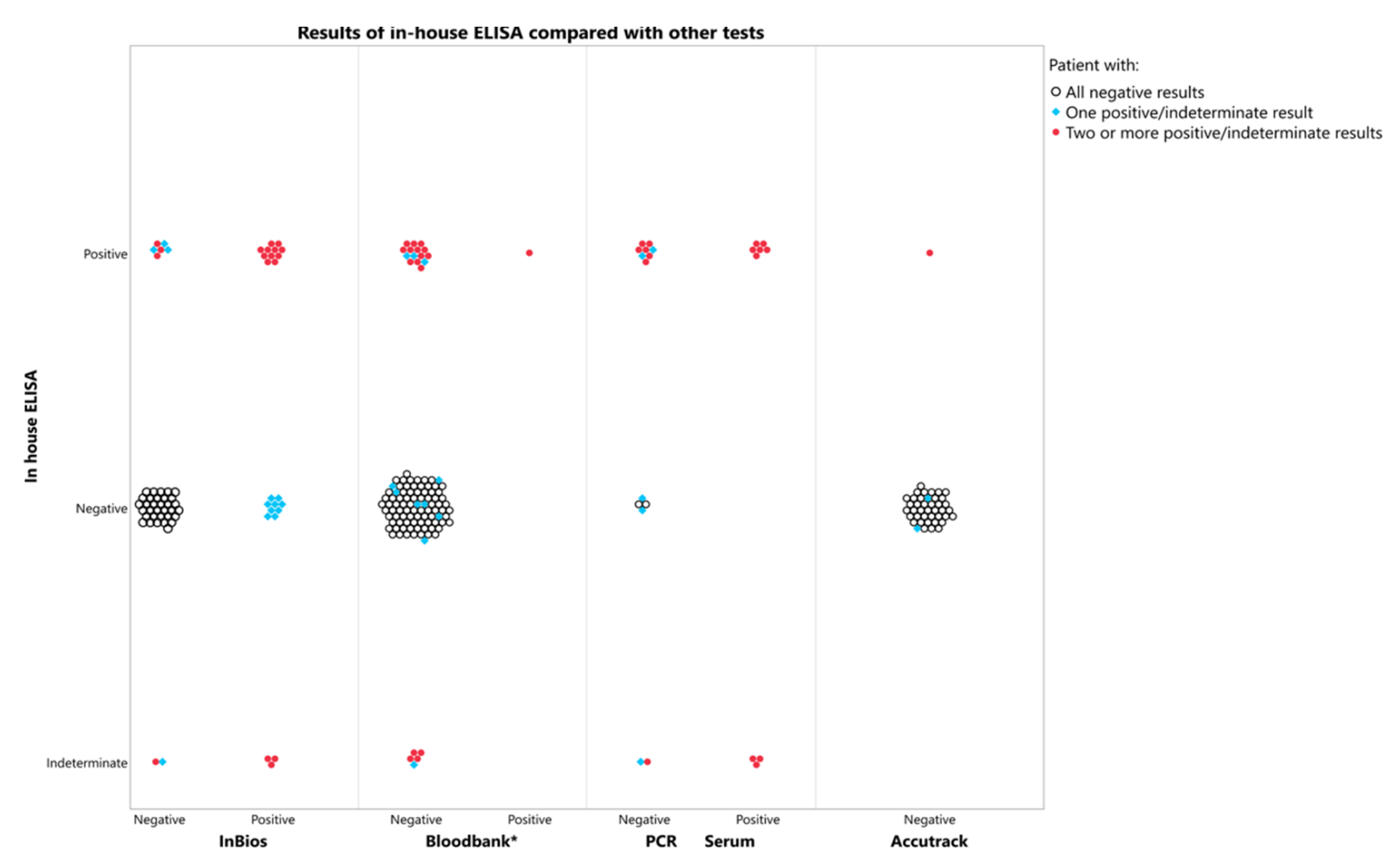

Figure 3. Test concordance with in-house ELISA results. ${ }^{*}$ Blood bank tests include: ABBOTT PRISM Chagas assay or BioRad Chagascreen ELISA.

\section{Discussion}

Our site is a main reference hospital in Mexico City and serves local residents as well as women referred for high-risk pregnancies. Despite the low reported awareness of $C D$ and its insect vector among our sample population, our results indicate ongoing undetected CD transmission in Mexico. The in-house ELISA, developed in Mexico with TcI strain Qro, found $11.33 \%$ of the sample population to be positive. Five positive and one indeterminate result on the screening test (in-house ELISA) could have been overlooked by commercial tests, as what happened with the Accutrack and blood bank ELISAs. Further testing with additional commercial assays and larger sample sizes could clarify this. The Inbios rapid test, used on a subset of 64 samples, found $35.94 \%(n=23)$ of this subset to be positive. A total of $39.13 \%$ of the 23 samples tested with PCR were found to be positive. Though these results may vary, they all attest to continuing maternal infection with T. cruzi.

There has been no country-wide seroprevalence study in Mexico that focuses on pregnant women, though a 2019 systematic review and meta-analysis of prevalence studies from various regions of Mexico, 2006-2017, found an estimated seroprevalence of 2.21\% among pregnant women [38]. In Mexico City specifically, a seroprevalence among pregnant women of $4.12 \%$ was found in $2012(\mathrm{n}=1448)$ [39]. In Palenque and Poza Rica, two other urban cities in Mexico, rates of 5\% and 3.5\% were found among pregnant women. Some studies in other regions report rates as high as 17\% [40]. Our study reinforces the importance of screening pregnant women for T. cruzi infection, as they have a higher seroprevalence than the general population: A 2005 study using blood bank specimens found a $0.37 \%$ seroprevalence in Mexico City [41]; compare this to the $2.12 \%$ seroprevalence found in pregnant women [38].

Currently, pregnant patients are not routinely screened for T. cruzi infection, despite the benefits for their own well-being as well as their child's. Pregnant patients identified as positive can then have their babies tested early for CD. Early detection is particularly important among infants, as it poses a unique opportunity to provide treatment that definitively clears the infection. Two pharmaceutical treatments for CD exist, Benznidazole and Nifurtimox, though both cause severe side effects in adults and do not ameliorate cardiac symptoms in chronic patients [42,43]. Both drugs have a less severe side effect 
profile in young children, making timely diagnosis of congenital CD crucial [44]. It is particularly important in non-endemic settings where re-infection is not expected. At-risk populations should undergo greater monitoring and surveillance for CD.

Strengthening access to healthcare is crucial to obtaining adequate screening for $\mathrm{CD}$. One suggested approach at the country level is developing initiatives tailored to the local health system and in alignment with general health goals and programs. Such is the case of Mexico and the Specific Action Program for the Prevention and Control of Chagas Disease 2013-2018, which actively engaged in activities to eliminate transfusion and congenital transmission [8]. Our study showed that while overall disease prevalence is low, in selected groups, there is a need to initiate screening and follow-up processes when appropriate. Another primary care-based screening pilot program in Boston found 3.8\% positive screening tests, demonstrating the feasibility of incorporation of $\mathrm{CD}$ screening in primary care in non-endemic settings [45]. Custom-made interdisciplinary initiatives that align with local goals and health projects are feasible, effective, and should be promoted to screen as many people as cost-effectively as possible in primary care settings.

Effective T. cruzi screening does however rely on reliable testing methods. Our study made use of many different assays, though each did not identify the same samples as positive. The varying abilities of serology tests to detect infections among the same set of patients could be due to the different T. cruzi strains used to develop and produce the tests and by the wide antibody response [46]. The T. cruzi species has six human-infective phylogenetic categories, called Discrete Typing Units (DTUs): TcI through TcVI. DTUs have distinct but overlapping geographic ranges and differing clinical outcomes and ecological characteristics [47]. TcI and TcIV have been detected in Mexico, with TcI being the most prevalent $[46,48,49]$. A serology test may best detect infections of the same lineage from which its antigens were cultivated. CD in the US and Mexico is mostly caused by TcI lineage parasites [50]; however, not all tests in our study were developed using this lineage. We did choose our in-house ELISA as a screening test because it was developed using a TcI lineage strain. Our study showed notable variation between all of the serological testing methods used, and while certainly not conclusive, it supports the idea that serological tests have varying efficacies among different populations due to the strain to which they were exposed. Our study also highlights the potential need for standardized guidelines for diagnosis and testing according to the predominant lineage. Previous work from our team has highlighted these needs as well [6].

Promising tests that could be incorporated into future studies include molecular assays for detection of congenital infection in babies. There is also a need to develop highly specific serological tests that can be easily implemented in community settings. This opens an important window of opportunity for the detection of CD in women and an early treatment for children, at a stage when the disease is curable with a low side effect profile.

\section{Study Limitations}

This study has limitations. Sample size restricts in-depth analysis of test performance and patient characteristics. While the diagnostic algorithm was completed according to current clinical practices at the institution, additional tests such as PCR, Inbios rapid test, and Accutrak Recombinant ELISA were not performed on all participants that had resulted negative according to the diagnostic algorithm due to resource constraints. Three patients with positive "in-house" ELISAs were not available to provide adequate blood samples for PCR testing. Moreover, genotyping was not conducted and therefore diagnostic performance cannot be associated with genetic characteristics of the parasite.

Despite our study limitations, we provide evidence for the necessity of prenatal screening of women from Chagas-endemic areas, and of the importance of revising current diagnostic approaches for T. cruzi infection. 


\section{Conclusions}

We provide evidence of ongoing T. cruzi infection in pregnant women in Mexico City, at a rate higher than that found by other studies in other Mexican states. Screening in the prenatal setting is of particular importance given the opportunity to treat both mother and infant. However, we encountered high variability between the serological screening tests used, which possibly highlights the need for region-specific T. cruzi assays. The lack of a reliable test for CD remains a diagnostic challenge in both endemic and non-endemic countries.

Supplementary Materials: The following are available online at https:/ /www.mdpi.com/article/10 $.3390 /$ tropicalmed7010008/s1, Table S1: Probes used in Multiplex qPCR Assay.

Author Contributions: Conceptualization, R.H.G., I.B., H.E.B., E.O. and M.M.-S.; methodology, R.H.G. and I.B.; investigation, I.B., A.R.-R., C.B.-G., E.A.F.-F., C.C.V.-C., A.B.-V., Y.B.-R., A.P.-G. and C.R.-B.; resources, I.B. and R.H.G.; data curation, I.B., A.R.-R., C.B.-G., E.A.F.-F., C.C.V.-C., A.B.-V., Y.B.-R., A.P.-G., C.R.-B. and I.C.; writing-original draft preparation, I.C. and M.M.-S.; writingreview and editing, I.C., M.M.-S. and H.E.B.; supervision, R.H.G., I.B. and H.E.B.; funding acquisition, R.H.G., M.M.-S., I.B., H.E.B., I.C. and E.O. All authors have read and agreed to the published version of the manuscript.

Funding: This research was funded by Research Program on Migration and Health (Programa de Investigación en Migracion y Salud) (PIMSA), Health Initiatives of the Americas, and by the Universidad Autónoma de México, grant number UNAM-PAPIIT AG201221.

Institutional Review Board Statement: The study was conducted according to the guidelines of the Declaration of Helsinki, and approved by the Ethics Board of the UNIVERSIDAD NACIONAL AUTONOMA DE MEXICO (protocol code 139-2017, 2017), and by the Ethics Committee of the HOSPITAL GENERAL DE MEXICO (protocol code HGM-DG-114-DI-2019, 2019).

Informed Consent Statement: Informed consent was obtained from all subjects involved in the study.

Data Availability Statement: All datasets available upon request to corresponding author.

Acknowledgments: The authors thank Rocely Cervantes-Sarabia and Cristina Cañeda-Guzmán for their help in processing the blood samples.

Conflicts of Interest: The authors declare no conflict of interest.

\section{References}

1. Lee, B.Y.; Bacon, K.M.; Bottazzi, M.E.; Hotez, P.J. Global Economic Burden of Chagas Disease: A Computational Simulation Model. Lancet Infect. Dis. 2013, 13, 342-348. [CrossRef]

2. Rassi, A., Jr.; Rassi, A.; Marin-Neto, J.A. Chagas Disease. Lancet 2010, 375, 1388-1402. [CrossRef]

3. Chadalawada, S.; Sillau, S.; Archuleta, S.; Mundo, W.; Bandali, M.; Parra-Henao, G.; Rodriguez-Morales, A.J.; Villamil-Gomez, W.E.; Suárez, J.A.; Shapiro, L.; et al. Risk of Chronic Cardiomyopathy Among Patients With the Acute Phase or Indeterminate Form of Chagas Disease: A Systematic Review and Meta-Analysis. JAMA Netw. Open 2020, 3, e2015072. [CrossRef]

4. Rassi, A., Jr.; Rassi, A.; Marcondes de Rezende, J. American Trypanosomiasis (Chagas Disease). Infect. Clin. N. Am. 2012, 26, 275-291. [CrossRef]

5. World Health Organization Chagas Disease in Latin America: An Epidemiological Update Based on 2010 Estimates. Wkly. Epidemiol. Rec. 2015, 90, 33-44. [CrossRef]

6. Miranda-Schaeubinger, M.; Chakravarti, I.; Freitas Lidani, K.C.; Omidian, Z.; Gilman, R.H. Systematic Review of the Epidemiology of Chagas Disease in the Americas: A Call for Standardized Reporting of Chagas Disease Prevalence. Curr. Trop. Med. Rep. 2019, 6, 23-34. [CrossRef]

7. Bern, C. Chagas' Disease. N. Engl. J. Med. 2015, 373, 1882. [CrossRef]

8. Rojo-Medina, J.; Ruiz-Matus, C.; Salazar-Schettino, P.M.; González-Roldán, J.F. Enfermedad de Chagas en México. Gac. Med. Mex. 2018, 154, 1209. [CrossRef] [PubMed]

9. Messenger, L.A.; Bern, C. Congenital Chagas Disease: Current Diagnostics, Limitations and Future Perspectives. Curr. Opin. Infect. Dis. 2018, 31, 415-421. [CrossRef] [PubMed]

10. Torrico, F.; Alonso-Vega, C.; Suarez, E.; Rodriguez, P.; Torrico, M.C.; Dramaix, M.; Truyens, C.; Carlier, Y. Maternal Trypanosoma Cruzi Infection, Pregnancy Outcome, Morbidity, and Mortality of Congenitally Infected and Non-Infected Newborns in Bolivia. Am. J. Trop. Med. Hyg. 2004, 70, 201-209. [CrossRef] [PubMed] 
11. Azogue, E.; Darras, C. Prospective Study of Chagas Disease in Newborn Children with Placental Infection Caused by Trypanosoma Cruzi (Santa Cruz-Bolivia). Rev. Soc. Bras. Med. Trop. 1991, 24, 105-109. [CrossRef] [PubMed]

12. Basombrio, M.A.; Nasser, J.; Segura, M.A.; Marco, D.; Sanchez Negrette, O.; Padilla, M.; Mora, M.C. The Transmission de Chagas Disease in Salta and the Detection of Congenital Cases. Med. B Aires 1999, 59 (Suppl. S2), 143-146.

13. Murcia, L.; Carrilero, B.; Munoz-Davila, M.J.; Thomas, M.C.; Lopez, M.C.; Segovia, M. Risk Factors and Primary Prevention of Congenital Chagas Disease in a Nonendemic Country. Clin. Infect. Dis. 2013, 56, 496-502. [CrossRef] [PubMed]

14. Bern, C.; Martin, D.L.; Gilman, R.H. Acute and Congenital Chagas Disease. Adv. Parasitol. 2011, 75, 19-47. [CrossRef]

15. Althabe, F.; For the Congenital Chagas Working Group; López, B.; Graiff, O.; Ramírez-Sierra, M.J.; Sosa-Estani, S.; Wesson, D.M.; Bustamante, N.; Alger, J.; Zúniga, C.; et al. Congenital Transmission of Trypanosoma Cruzi in Argentina, Honduras, and Mexico: An Observational Prospective Study. Am. J. Trop. Med. Hyg. 2018, 98, 478-485. [CrossRef]

16. Howard, E.J.; Xiong, X.; Carlier, Y.; Sosa-Estani, S.; Buekens, P. Frequency of the Congenital Transmission of Trypanosoma Cruzi: A Systematic Review and Meta-Analysis. BJOG 2014, 121, 22-33. [CrossRef]

17. Messenger, L.A.; Gilman, R.H.; Verastegui, M.; Galdos-Cardenas, G.; Sanchez, G.; Valencia, E.; Sanchez, L.; Malaga, E.; Rendell, V.R.; Jois, M.; et al. Toward Improving Early Diagnosis of Congenital Chagas Disease in an Endemic Setting. Clin. Infect. Dis. 2017, 65, 268-275. [CrossRef]

18. Pan American Health Organization. Guidelines for the Diagnosis and Treatment of Chagas Disease; Pan American Health Organization: Washington, DC, USA, 2019. Available online: https://iris.paho.org/bitstream/handle/10665.2/49653/9789275120439_eng.pdf (accessed on 6 October 2021).

19. Stanaway, J.D.; Roth, G. The Burden of Chagas Disease: Estimates and Challenges. Glob. Heart 2015, 10, 139-144. [CrossRef]

20. Verani, J.R.; Seitz, A.; Gilman, R.H.; LaFuente, C.; Galdos-Cardenas, G.; Kawai, V.; de LaFuente, E.; Ferrufino, L.; Bowman, N.M.; Pinedo-Cancino, V.; et al. Geographic Variation in the Sensitivity of Recombinant Antigen-Based Rapid Tests for Chronic Trypanosoma Cruzi Infection. Am. J. Trop. Med. Hyg. 2009, 80, 410-415. [CrossRef]

21. Guzmán-Gómez, D.; López-Monteon, A.; de la Soledad Lagunes-Castro, M.; Álvarez-Martínez, C.; Hernández-Lutzon, M.J.; Dumonteil, E.; Ramos-Ligonio, A. Highly Discordant Serology against Trypanosoma Cruzi in Central Veracruz, Mexico: Role of the Antigen Used for Diagnostic. Parasit. Vectors 2015, 8, 466. [CrossRef] [PubMed]

22. Truyens, C.; Dumonteil, E.; Alger, J.; Cafferata, M.L.; Ciganda, A.; Gibbons, L.; Herrera, C.; Sosa-Estani, S.; Buekens, P. Geographic Variations in Test Reactivity for the Serological Diagnosis of Trypanosoma Cruzi Infection. J. Clin. Microbiol. 2021, 59, e01062-21. [CrossRef]

23. Viotti, R.; Vigliano, C.; Lococo, B.; Bertocchi, G.; Petti, M.; Alvarez, M.G.; Postan, M.; Armenti, A. Long-Term Cardiac Outcomes of Treating Chronic Chagas Disease with Benznidazole versus No Treatment: A Nonrandomized Trial. Ann. Intern. Med. 2006, 144, 724. [CrossRef]

24. Tornheim, J.A.; Lozano Beltran, D.F.; Gilman, R.H.; Castellon, M.; Solano Mercado, M.A.; Sullca, W.; Torrico, F.; Bern, C. Improved Completion Rates and Characterization of Drug Reactions with an Intensive Chagas Disease Treatment Program in Rural Bolivia. PLoS Negl. Trop. Dis. 2013, 7, e2407. [CrossRef] [PubMed]

25. Carlier, Y.; Sosa-Estani, S.; Luquetti, A.O.; Buekens, P. Congenital Chagas Disease: An Update. Mem. Inst. Oswaldo Cruz 2015, 110, 363-368. [CrossRef]

26. Sanchez, J.D. Conclusions and Recommendations. In Chagas Disease in the Americas: A Review of the Current Public Health Situation and $a$ Vision for the Future; PAHO/WHO: Washington, DC, USA, 2018.

27. Stimpert, K.K.; Montgomery, S.P. Physician Awareness of Chagas Disease, USA. Emerg. Infect. Dis. 2010, 16, 871-872. [CrossRef]

28. Picado, A.; Angheben, A.; Marchiol, A.; Alarcón de Noya, B.; Flevaud, L.; Pinazo, M.J.; Gállego, M.; Meymandi, S.; Moriana, S. Development of Diagnostics for Chagas Disease: Where Should We Put Our Limited Resources? PLoS Negl. Trop. Dis. 2017, 11, e0005148. [CrossRef]

29. Harris, P.A.; Taylor, R.; Minor, B.L.; Elliott, V.; Fernandez, M.; O’Neal, L.; McLeod, L.; Delacqua, G.; Delacqua, F.; Kirby, J.; et al. The REDCap Consortium: Building an International Community of Software Platform Partners. J. Biomed. Inform. 2019, 95, 103208. [CrossRef] [PubMed]

30. Harris, P.A.; Taylor, R.; Thielke, R.; Payne, J.; Gonzalez, N.; Conde, J.G. Research Electronic Data Capture (REDCap)—A MetadataDriven Methodology and Workflow Process for Providing Translational Research Informatics Support. J. Biomed. Inform. 2009, 42, 377-381. [CrossRef]

31. Iborra-Bendicho, M.A.; Albert-Hernández, M.; Márquez-Contreras, C.; Segovia-Hernández, M. ARCHITECT Chagas ${ }^{\circledR}$ : Una nueva herramienta diagnóstica en la enfermedad de Chagas. Enfermedades Infecc. Microbiol. Clín. 2012, 30, 463-465. [CrossRef] [PubMed]

32. Espinoza, B.; Rico, T.; Sosa, S.; Oaxaca, E.; Vizcaino-Castillo, A.; Caballero, M.L.; Martínez, I. Mexican Trypanosoma Cruzi (TCI) Strains with Different Degrees of Virulence Induce Diverse Humoral and Cellular Immune Responses in a Murine Experimental Infection Model. J. Biomed. Biotechnol. 2010, 2010, 1-10. [CrossRef] [PubMed]

33. Ryan, J.R.; Smithyman, A.M.; Rajasekariah, G.-H.; Hochberg, L.; Stiteler, J.M.; Martin, S.K. Enzyme-Linked Immunosorbent Assay Based on Soluble Promastigote Antigen Detects Immunoglobulin M (IgM) and IgG Antibodies in Sera from Cases of Visceral and Cutaneous Leishmaniasis. J. Clin. Microbiol. 2002, 40, 1037-1043. [CrossRef] [PubMed]

34. World Health Organization. Anti-Trypanosoma Cruzi Assays: Operational Characteristics, Report 1; World Health Organization: Geneva, Switzerland, 2010; ISBN 978-92-4-150029-6. 
35. Shah, V.; Ferrufino, L.; Gilman, R.H.; Ramirez, M.; Saenza, E.; Malaga, E.; Sanchez, G.; Okamoto, E.E.; Sherbuck, J.E.; Clark, E.H.; et al. Field Evaluation of the InBios Chagas Detect plus Rapid Test in Serum and Whole-Blood Specimens in Bolivia. Clin. Vaccine Immunol. 2014, 21, 1645-1649. [CrossRef]

36. Ramírez, J.C.; da Cruz Moreira, O. Assessing Parasite Load in Chagas Disease Patients by Quantitative Multiplex Real-Time PCR. In T. cruzi Infection; Gómez, K.A., Buscaglia, C.A., Eds.; Methods in Molecular Biology; Springer: New York, NY, USA, 2019; Volume 1955, pp. 215-225. ISBN 978-1-4939-9147-1.

37. StataCorp. Stata Statistical Software: Release 14; StataCorp: College Station, TX, USA, 2015.

38. Arnal, A.; Waleckx, E.; Rico-Chávez, O.; Herrera, C.; Dumonteil, E. Estimating the Current Burden of Chagas Disease in Mexico: A Systematic Review and Meta-Analysis of Epidemiological Surveys from 2006 to 2017. PLoS Negl. Trop. Dis. 2019, 13, e0006859. [CrossRef]

39. Cardoso, E.J.; Valdez, G.C.; Campos, A.C.; de la Luz Sanchez, R.; Mendoza, C.R.; Hernandez, A.P.; Ramirez, M.H.; Habana, J.R.; Gonzalez, E.B.; Matzumura, P.D.; et al. Maternal Fetal Transmission of Trypanosoma Cruzi: A Problem of Public Health Little Studied in Mexico. Exp. Parasitol. 2012, 131, 425-432. [CrossRef]

40. López-Monteon, A.; Montero, H.; González-Constantino, R.S.; Limón-Flores, A.Y.; Varela-Cardoso, M.; Luna-Hernández, G.; Dumonteil, E.; Ramos-Ligonio, A. Seroprevalence of Trypanosoma Cruzi Infection in Pregnant Women Suggests a High Risk for Congenital Transmission in Central Veracruz, Mexico. Acta Parasitol. 2020, 65, 661-668. [CrossRef]

41. Hernández-Becerril, N.; Mejía, A.M.; Ballinas-Verdugo, M.A.; Garza-Murillo, V.; Manilla-Toquero, E.; López, R.; Trevethan, S.; Cardenas, M.; Reyes, P.A.; Hirayama, K.; et al. Blood Transfusion and Iatrogenic Risks in Mexico City: Anti-Trypanosoma Cruzi Seroprevalence in 43,048 Blood Donors, Evaluation of Parasitemia, and Electrocardiogram Findings in Seropositive. Mem. Inst. Oswaldo Cruz 2005, 100, 111-116. [CrossRef] [PubMed]

42. Marin-Neto, J.A.; Rassi, A., Jr.; Avezum, A., Jr.; Mattos, A.C.; Rassi, A.; Morillo, C.A.; Sosa-Estani, S.; Yusuf, S.; Investigators, B. The BENEFIT Trial: Testing the Hypothesis That Trypanocidal Therapy Is Beneficial for Patients with Chronic Chagas Heart Disease. Mem. Inst. Oswaldo Cruz 2009, 104 (Suppl. S1), 319-324. [CrossRef] [PubMed]

43. Sueth-Santiago, V.; Decote-Ricardo, D.; Morrot, A.; Freire-de-Lima, C.G.; Lima, M.E.F. Challenges in the Chemotherapy of Chagas Disease: Looking for Possibilities Related to the Differences and Similarities between the Parasite and Host. World J. Biol. Chem. 2017, 8, 57-80. [CrossRef] [PubMed]

44. Paulino, M.; Iribarne, F.; Dubin, M.; Aguilera-Morales, S.; Tapia, O.; Stoppani, A.O.M. The Chemotherapy of Chagas' Disease: An Overview. Available online: https:/ / www.ingentaconnect.com/content/ben/mrmc/2005/00000005/00000005/art00007 (accessed on 5 November 2018).

45. Manne-Goehler, J.; Davis, J.; Perez, J.H.; Collins, K.; Harakawa, H.; Hochberg, N.; Hamer, D.; Barnett, E.; Köhler, J. 442. The Results of a Primary Care-Based Screening Program for Trypanosoma Cruzi in East Boston, Massachusetts. Open Forum Infect. Dis. 2018, 5, S166. [CrossRef]

46. Zingales, B. Trypanosoma Cruzi Genetic Diversity: Something New for Something Known about Chagas Disease Manifestations, Serodiagnosis and Drug Sensitivity. Acta Trop. 2018, 184, 38-52. [CrossRef]

47. Messenger, L.A.; Miles, M.A.; Bern, C. Between a Bug and a Hard Place: Trypanosoma Cruzi Genetic Diversity and the Clinical Outcomes of Chagas Disease. Expert Rev. Anti-Infect. Ther. 2015, 13, 995-1029. [CrossRef] [PubMed]

48. Dorn, P.; Buekens, P.; Hanford, E. Whac-a-Mole: Future Trends in Chagas Transmission and the Importance of a Global Perspective on Disease Control. Future Microbiol. 2007, 2, 365-367. [CrossRef]

49. Zingales, B.; Miles, M.A.; Campbell, D.A.; Tibayrenc, M.; Macedo, A.M.; Teixeira, M.M.; Schijman, A.G.; Llewellyn, M.S.; Lages-Silva, E.; Machado, C.R.; et al. The Revised Trypanosoma Cruzi Subspecific Nomenclature: Rationale, Epidemiological Relevance and Research Applications. Infect. Genet. Evol. 2012, 12, 240-253. [CrossRef] [PubMed]

50. Herrera, C.; Truyens, C.; Dumonteil, E.; Alger, J.; Sosa-Estani, S.; Cafferata, M.L.; Gibbons, L.; Ciganda, A.; Matute, M.L.; Zuniga, C.; et al. Phylogenetic Analysis of Trypanosoma Cruzi from Pregnant Women and Newborns from Argentina, Honduras, and Mexico Suggests an Association of Parasite Haplotypes with Congenital Transmission of the Parasite. J. Mol. Diagn. JMD 2019, 21, 1095-1105. [CrossRef] [PubMed] 